\title{
Validated Stability-Indicating Assay UHPLC Method for Simultaneous Analysis of Saxagliptin and Metformin in Fixed-Dose Combinations
}

\author{
Rahul P. Umbarkar 1,* (D), Abhilasha Mittal ${ }^{2}$, Manoj. S. Charde ${ }^{3}$ \\ 1 NIMS University, Jaipur, Rajasthan India 303121; rpumbarkar@ gmail.com (R.P.U.); \\ 2 Department pharmaceutical chemistry, Institute of Pharmacy, NIMS University, Jaipur, Rajasthan India 303121; \\ abhilashamittal24@gmail.com (A.M.); \\ 3 Government College of Pharmacy, Karad, 415110 Maharashtra; manojudps@ rediffmail.com (M.S.C.); \\ * Correspondence: rpumbarkar@gmail.com (R.P.U.);
}

Received: 18.05.2021; Revised: 20.06.2021; Accepted: 25.06.2021; Published: 8.08.2021

\begin{abstract}
A Saxagliptin (SAX) and Metformin (MET) fixed-dose combination (FDC) can improve the chances of achieving optimal glycaemic control in type 2 diabetes mellitus subjects. Accordingly, the scientific novelty of design work was to develop a specific and precise stability-indicating UHPLC assay method for simultaneous quantification of cited drugs in extended-release FDC's. The reversedphase UHPLC resolution was analyzed with the assistance of UPLC BEH C ${ }_{18}(150 \mathrm{~mm} \times 2.1 \mathrm{~mm})$ with $1.7 \mu \mathrm{m}$ particle size column at ambient temperature using a solvent system in a proportion of $(85: 15 \%$ $v / v$ ) potassium dihydrogen orthophosphate buffer and acetonitrile, with $0.4 \mathrm{~mL} / \mathrm{min}$ rate of flow of a solvent system. The analytes were supervised at $220 \mathrm{~nm}$ by employing photodiode array recognition. The retention times of analytes SAX and MET were $2.687 \pm 0.022 \mathrm{~min}$ and $1.856 \pm 0.03 \mathrm{~min}$, respectively. The SAX and MET have confirmed the linearity ranges of $10-60 \mu \mathrm{g} / \mathrm{mL}$ and $100-600$ $\mu \mathrm{g} / \mathrm{mL}$, with 0.9989 and 0.9979 determination coefficients. The UHPLC method was effectually validated concerning the accuracy, precision, sensitivity, robustness, ruggedness, selectivity, and specificity. Moreover, the anticipated UHPLC method's capability to analyzed the SAX and MET with no obstruction from degradation products.
\end{abstract}

Keywords: UHPLC method; Saxagliptin; Metformin; stability-indicating assay; fixed-dose combinations.

(C) 2021 by the authors. This article is an open-access article distributed under the terms and conditions of the Creative Commons Attribution (CC BY) license (https://creativecommons.org/licenses/by/4.0/).

\section{Introduction}

Type 2 diabetes (T2DM) is a highly complicated and emerging disease characterized by various pathophysiological factors: impaired insulin secretion, a lessened incretin effect, elevated insulin sensitivity, and enhanced hepatic glucose production [1]. Metformin hydrochloride (MET) is the first-line therapy for pharmacological management for subjects with T2DM. Its favorable overall profile includes glucose-lowering potential and minimal risk of hypoglycemia. Its main action is a reduction in hepatic glucose outflow [2,3]. Chemically, MET is 1-carbamimidamido-N,N-dimethylmethanimidamide depicted in Figure 1(a). Meanwhile, combination pharmacological therapies are often needed to address the numerous underlying pathophysiological mechanisms that cause hyperglycemia. So, if MET struggles to maintain glycaemic regulation, various options can be considered, but there is no solid unanimity $[4,5]$. 
Dipeptidyl peptidase-4 therapeutic's, namely Saxagliptin (SAX), is the recent oral combination pharmacological activity choice. Chemically SAX is, (1S,3S,5S)-2-[(2S)-2amino-2-(3-hydroxy-1-adamantyl)acetyl]-2-azabicyclo[3.1.0]hexane-3-carbonitrile depicted in Figure 1(b). Compared to adding a sulfonylurea or a thiazolidinedione to MET, DPP-4 therapeutics provide a remarkably similar enhancement in glucose regulation. However, they are consistent with an improved tolerance balance combining neutral influences on body weight and the absence of hypoglycaemic threat. Hence, a fixed-dose combination (FDC's) of SAX and MET combines these mechanisms of action in a single tablet, thereby reducing the tablet burden and the potential for increased patient compliance with the convenience of oncedaily dosing $[6,7]$.<smiles>CN(C)C(=N)NC(=N)N</smiles>

(a)

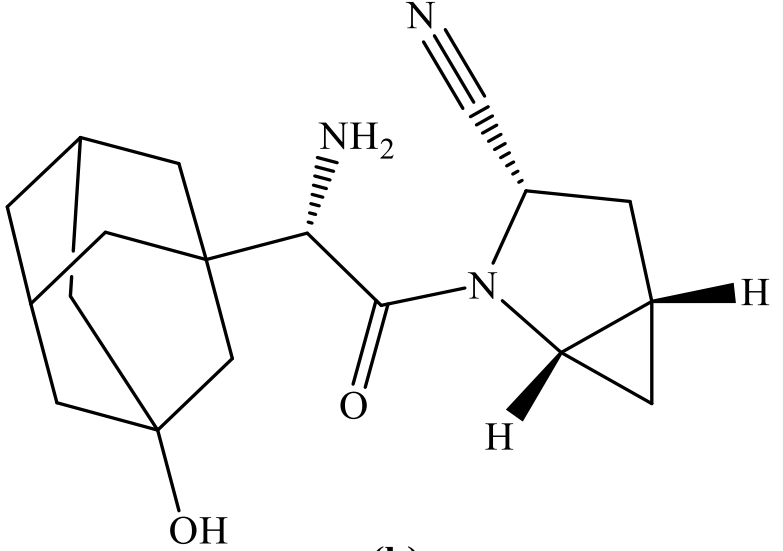

(b)

Figure 1. (a) Chemical structure of MET; (b) Chemical structure of SAX.

According to its therapeutic benefits, SAX and MET have seemed to have many potential efficiencies in managing various pathophysiological failings.

Designing a specific and precise analytical assay method is highly advantageous for simultaneous quantification of SAX and MET in pharmaceutical FDC's.

Numerous analytical literature search reports have been addressed for the analysis of cited drugs alone or in combined FDC's with other therapeutic agents by exploring LC-MS/MS [8-15], HPLC [16-25], and HPTLC [26-34] in pharmaceutical matrices as well in bioanalytical samples. Consequently, none of these approaches have been deemed highly acceptable due to higher retention times of analytes, excessive consumption of polar organic solvents, more waste generation, higher rate of flows, and unproductive analysis due to an operational cost. However, in order to overcome disadvantage associated with these analytical reports, the ultra-high-performance liquid chromatography (UHPLC) technique have been deemed extremely useful for enabling rapid determination of analytes, requiring lowers process cycle time ensures end-product efficiency by reducing operating costs and shortening run times, faster-resolving power making it more selective and sensitive. Moreover, it uses a novel column material with a minimum particle size to improve sensitivity and reduce polar organic solvent's excessive consumption.

Therefore, the present work was accordingly undertaken by employing the merits mentioned earlier to design a cost-effective, rapid, and precise UHPLC assay method for quantifying SAX and MET in the pharmaceutical FDC's. Moreover, the application of proposed work to assessed intrinsic stability behavior of the SAX and MET under distinct conditions of stressors. 


\section{Materials and Methods}

\subsection{Pharmaceutical standards.}

Glenmark Pharmaceuticals LTD., India, generously supported saxagliptin (SAX). Its purity was labeled to be $99.95 \%$. Umedica Laboratories PVT. LTD., India generously supported metformin hydrochloride (MET). Its purity was labeled to be $99.93 \%$.

\subsection{Pharmaceutical FDC's.}

Kombiglyze XR $5 \mathrm{mg} / 1000 \mathrm{mg}$ and Kombiglyze XR $5 \mathrm{mg} / 500 \mathrm{mg}$ tablets are manufactured by AstraZeneca Pharmaceuticals LP., Mount Vernon, Indiana, USA, and Imported and Marketed by AstraZeneca Pharm. LTD., India.

\subsection{Chemicals and reagents.}

Methanol HPLC grade was purchased from Merck, LTD., India, and potassium dihydrogen phosphate buffer and orthophosphoric acid (OPA) analytical grade were supplied from Loba Chemie PVT. LTD., India.

\subsection{Selection of solvent.}

The solubility of SAX and MET were tested in various specified solvents; methanol was selected to be the best solvent for both analytes.

\subsection{Stock standard solution preparation.}

Stock standard solutions were prepared by the precise quantity of $5 \mathrm{mg}$ of SAX, and $1000 \mathrm{mg}$ of MET were effectively solubilized into two distinct $100 \mathrm{~mL}$ of calibrated flask consisting of $50 \mathrm{~mL}$ of methanol, manually shaken for $10 \mathrm{~min}$. Finally, the volume was diluted to the point of the calibrated flask to obtained $50 \mu \mathrm{g} / \mathrm{mL}$ and $10000 \mu \mathrm{g} / \mathrm{mL}$ of SAX and MET concentrations.

\subsection{Working solution of analysis.}

A working solution of SAX and MET was prepared using moving accurate volume of $0.1 \mathrm{~mL}$ into $10 \mathrm{~mL}$ of the calibrated flask from standard stock solutions. The volume was diluted to the mark with the same to get the $5 \mu \mathrm{g} / \mathrm{mL}$ and $100 \mu \mathrm{g} / \mathrm{mL}$ concentrations of SAX and MET.

\subsection{Condition for resolution of SAX and MET.}

The identification and quantification of a compound of interest (SAX and MET) from non-interest components with acceptable selectivity, specificity, and sensitivity with rapid analysis were verified on UPLC BEH C 18 (150 $\mathrm{mm} \times 2.1 \mathrm{~mm})$ with $1.7 \mu \mathrm{m}$ particle size column at ambient temperature using a solvent system in a proportion of $(85: 15 \% \mathrm{v} / \mathrm{v})$ potassium dihydrogen orthophosphate buffer and acetonitrile; $\mathrm{pH} 4.5$ was adjusted with $0.1 \%$ OPA. Before executing chromatographic analysis, the solvent system was filtered through a $0.2 \mu \mathrm{m}$ membrane (Ultipor N66 Nylon 6,6) and sonication for $20 \mathrm{~min}$. A $10 \mu \mathrm{L}$ of fixed volume (working solution) was injected. The chromatogram was studied at a detection wavelength of 
$220 \mathrm{~nm}$. Ahead of the injection of the working solution, UPLC BEH C18 column was saturated for at least 20 minutes with the solvent system flowing through the column.

\subsection{Development of plots for linearity experiment.}

The calibration plots for SAX and MET were assessed using the six working solutions. The same was prepared using the precise aliquots $(2-12 \mathrm{~mL}$ of SAX) and $(0.1-0.6 \mathrm{~mL}$ of MET) from standard stock solutions were accurately moved into the $10 \mathrm{~mL}$ series of a calibrated flask, and the volume was diluted to the mark of a calibrated flask with a solvent system to get the $10-60 \mu \mathrm{g} / \mathrm{mL}$ and $100-600 \mu \mathrm{g} / \mathrm{mL}$ concentrations of SAX and MET, respectively.

\subsection{Assay of marketed FDC's of SAX and MET.}

The assay of SAX and MET in the marketed FDC's were performed for two different pharmaceutical matrices. To estimate the SAX and MET in tablet matrix, twenty tablets of Kombiglyze XR (label claim SAX- $5 \mathrm{mg}$ and MET- $1000 \mathrm{mg}$ and label claim SAX- $5 \mathrm{mg}$ and MET- $500 \mathrm{mg}$ ) were evaluated to estimate the average weight of the tablets and then ground and mixed through pestle and mortar. A portion of tablet powder corresponding to one tablet's weight was precisely solubilized separately into $50 \mathrm{~mL}$ of methanol and sonicated for $15 \mathrm{~min}$ to obtain the complete dissolution of SAX and MET and before made the volume to mark with same; were filtered through a $0.45 \mu \mathrm{m}$ membrane. The suitable volume was diluted with methanol to get the concentrations of $20 \mu \mathrm{g} / \mathrm{mL}$ and $200 \mu \mathrm{g} / \mathrm{mL}$ of SAX and MET analyzed according to the section 2.7 condition of resolution for SAX and MET.

\subsection{Stress degradation studies for SAX and MET.}

The present UHPLC method was used to address the intrinsic stability behavior of the SAX and MET under distinct conditions of stressors. It was investigated according to Q1A (R2) guidelines of ICH references for hydrolysis, oxidation, thermal (dry heat and wet heat stress), and photolysis as per the references of Q1B. The stressors, the preference of their concentration, and sample's processing were predicated on a pre-developed research experiment. Subsequently, the SAX and MET were practically insoluble in water; thus, the stress studies were initiated by dissolving the stressor in methanol. The slight changes in mobile phase composition and flow rate were made to resolve all the potential degradants [35-37].

\subsubsection{Acidic hydrolysis.}

Acidic hydrolytic stress was stimulated by separately solubilizing a precisely weighted quantity of SAX and MET equal to $10 \mathrm{mg}$ in $1 \mathrm{M}$ methanolic $\mathrm{HCl}$ and refluxing the resulting solution at $80^{\circ} \mathrm{C}$ for $\mathrm{SAX}$ and $60^{\circ} \mathrm{C}$ for MET in a thermostatic water bath for $2 \mathrm{~h}$ and $45 \mathrm{~min}$, respectively. The adequate aliquots of samples $(1 \mathrm{~mL})$ were removed and neutralized with equal strength of methanolic $\mathrm{NaOH}$ solution before being UHPLC analyzed.

\subsubsection{Alkaline hydrolysis.}

Alkaline hydrolytic stress was stimulated by separately solubilizing a precisely weighted quantity of SAX and MET equal to $10 \mathrm{mg}$ in $2 \mathrm{M}$ methanolic $\mathrm{NaOH}$ and refluxing the resulting solution at $80^{\circ} \mathrm{C}$ for $\mathrm{SAX}$ in a thermostatic water bath for $2 \mathrm{~h}$. The appearing solution of MET was preserved in the dark at room temperature for 3 days. The adequate 
aliquots of samples $(1 \mathrm{~mL})$ were removed and neutralized with equal strength of methanolic $\mathrm{HCl}$ solution before being UHPLC analyzed.

2.10.3. Neutral hydrolysis.

To address hydrolysis influence in a neutral setting, it was stimulated by separately solubilizing a precisely weighted quantity of SAX and MET equal to $10 \mathrm{mg}$ in $10 \mathrm{~mL}$ of methanol as a stressor and preserved in the dark at room temperature for 7 days. The adequate aliquots of samples $(0.1 \mathrm{~mL})$ were removed and diluted with the same before being UHPLC analyzed.

\subsubsection{Oxidative degradation.}

Oxidative stress was stimulated by separately solubilizing a precisely weighted quantity of SAX and MET equal to $10 \mathrm{mg}$ in $6 \% \mathrm{H}_{2} \mathrm{O}_{2}$, and the calibrated flask volume was made to point with methanol. The appearing solution of MET was preserved in the dark at room temperature for 3 days. The adequate aliquots of samples $(0.1 \mathrm{~mL})$ were removed and marked with the same before being UHPLC analyzed.

\subsubsection{Photodegradation.}

The photolysis was initiated by disclosing the samples of SAX and MET (spreading as a thin layer on a petri dish) to the illumination of $\geq 360 \mathrm{Wh} / \mathrm{m}^{2}$ at $30^{\circ} \mathrm{C}$ with $\mathrm{UV}$ radiation, i.e., for short UV-254 nm and long UV-360 nm for 6 consecutive days. The samples were withdrawn adequately, diluted before being UHPLC analyzed.

\subsubsection{Thermal degradation (dry and wet heat).}

The thermal (dry heat) stress was initiated by around acquainting with $50 \mathrm{mg}$ of SAX and $100 \mathrm{mg}$ of MET separately into a sealed ampoule and placing it into the digital controlled thermostatic hot air oven at $80{ }^{\circ} \mathrm{C}$ for $10 \mathrm{~h}$. From the same, $10 \mathrm{mg}$ of drugs were measured, solubilized, and diluted with a solvent system in calibrated flasks of $10 \mathrm{~mL}$.

The wet heat stress was initiated by SAX and MET $(1 \mathrm{mg} / \mathrm{mL})$ into the digital controlled thermostatic hot air oven at $80{ }^{\circ} \mathrm{C}$ for $5 \mathrm{~h}$. From it, $10 \mathrm{mg}$ of drugs were measured, solubilized, and diluted with a solvent system in calibrated flasks of $10 \mathrm{~mL}$.

\subsection{Validation of designed UHPLC method.}

The Q2(R1) (confirmation), Q1A(R2) (stress studies), and Q1B (photolysis) procedures of the International Council for Harmonization (ICH) of Technical Requirements for Pharmaceuticals for Human Use present were employed for confirmation of the designed stability-indicating UHPLC assay method for simultaneous quantification for SAX and MET in FDC's [34-36].

\section{Results and discussion}

\subsection{Optimization of a solvent system.}

With the view to resolved and quantified the SAX and MET from the degradation products and as on after from tablet matrices; are mostly meticulous based upon several variables, main polarities of SAX and MET, the solubility of drugs into specific and 
combination of solvents and also on reported data on the literature. Therefore, the choice of solvent system composition for resolution and quantification of SAX and MET were carried out with different compositions of solvent systems. Principally, acetonitrile $(100 \% \mathrm{v} / \mathrm{v})$ was confirmed, but both drug candidates' early elution and splitting were observed with poor resolution. Accordingly, efforts were taken to use different proportions of acetonitrile: water extending from 90:10 \% v/v to 20:80 \% v/v were employed, and it was noticed that deprived separation was observed; therefore, in order to improve the resolution between the SAX and MET, potassium dihydrogen orthophosphate buffer was tested in different proportion with acetonitrile. Consequently, an excellent resolution was noticed in the case of $(85: 15 \% v / v)$ potassium dihydrogen orthophosphate buffer: acetonitrile with extensive tailing of both peaks was sawed. So, the extensive tailing of both analytes was minimized by adjusting the $\mathrm{pH}$ of the buffer to 4.5 with $0.1 \%$ OPA.

Moreover, to reduce the influence of the solvent system, the samples were prepared using the solvent system. In conclusion, the solvent system comprises a proportion of acetonitrile: potassium dihydrogen orthophosphate buffer $(15: 85 \% \mathrm{v} / \mathrm{v}, \mathrm{pH}-4.5$ adjusted with $0.1 \%$ OPA) was demonstrated good symmetrical peaks shape, and excellent resolution of both eluents was also appropriate due to acceptable system suitability tests. The total analysis time for quantification of SAX and MET was below $4 \mathrm{~min}$. The retention times (Rt) of SAX and MET were $2.687 \pm 0.022 \mathrm{~min}$ and $1.856 \pm 0.03 \mathrm{~min}$; respectively, the chromatogram is depicted in Figure 2.

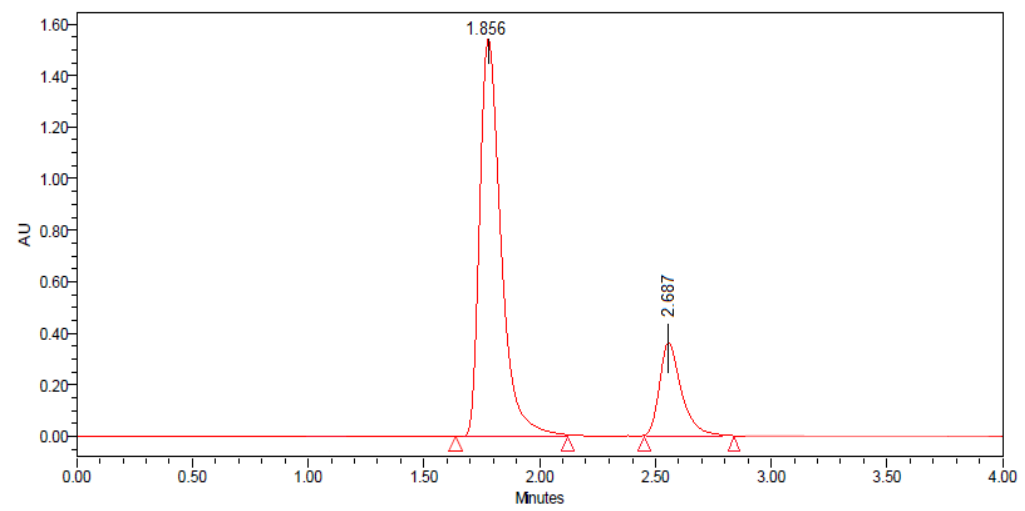

Figure 2. Chromatogram of MET and SAX.

\subsection{Validation of UHPLC method.}

The optimized conditions for the resolution of SAX and MET were further explored to validate the designed UHPLC method.

\subsubsection{System suitability evaluation.}

To assess the quality assurance of the designed chromatographic method, the metrics of system suitability were confirmed. The tests like theoretical plates, tailing factor, and resolution were assessed with concentrations $5 \mu \mathrm{g} / \mathrm{mL}$ and $100 \mu \mathrm{g} / \mathrm{mL}$ of SAX and MET (six $100 \%$ determinations). The standard deviation and relative standard deviation (\%) for peak area and $\mathrm{R} t$ were determined. The findings revealed in Table 1 are within statistically acceptable limits; in all determinations, the theoretical plates were more than 2000, demonstrating excellent column efficiency throughout the chromatographic investigation. The tailing factor was recorded to be less than $2 \%$, signifying the outstanding SAX and MET peak symmetries. 


\begin{tabular}{|c|c|c|c|c|c|c|c|c|}
\hline \multicolumn{9}{|c|}{ Table 1. System suitability testing. } \\
\hline \multirow{2}{*}{$\begin{array}{l}\text { Parameters } \\
\text { Analytes } \\
\end{array}$} & \multicolumn{2}{|c|}{ Retention times (Rt) } & \multicolumn{2}{|c|}{$\begin{array}{l}\text { Theoretical plates (USP } \\
\text { plate count) }\end{array}$} & \multicolumn{2}{|c|}{ Tailing factor } & \multicolumn{2}{|c|}{ Resolution } \\
\hline & SAX & MET & SAX & MET & SAX & MET & SAX & MET \\
\hline $\begin{array}{l}\text { Results } \\
{[n=6 \pm S D]}\end{array}$ & $\begin{array}{l}2.687 \pm \\
0.022\end{array}$ & $\begin{array}{l}1.856 \pm \\
0.03\end{array}$ & $\begin{array}{l}2321.68 \pm \\
0.12\end{array}$ & $6257.15 \pm 0.26$ & $\begin{array}{l}1.42 \pm \\
0.02\end{array}$ & $\begin{array}{l}1.45 \pm \\
0.04\end{array}$ & & 39 \\
\hline
\end{tabular}

\subsubsection{Calibration plots.}

The calibration plots were established using the six working solutions in the $10-60$ $\mu \mathrm{g} / \mathrm{mL}$ and $100-600 \mu \mathrm{g} / \mathrm{mL}$ concentrations range of SAX and MET, respectively. The calibration plots of peak area against the $\mu \mathrm{g} / \mathrm{mL}$ concentrations for SAX and MET were plotted and analyzed using the linear regression equation to develop a relationship as a calibration curve. The equation of the calibration plots (i.e., linear regression) were $y=5717.8 x+12076$ with determination coefficient $\left(r^{2}\right.$ 0.9989) for SAX and $y=6746.8 x+131809$ with determination coefficient $\left(\mathrm{r}^{2} 0.9979\right)$, revealed an excellent response relationship against the concentrations in $\mu \mathrm{g} / \mathrm{mL}$.

\subsubsection{Accuracy.}

The accuracy of the designed UHPLC method was addressed with \% recovery. It was investigated at 80, 100, and $120 \%$ levels. For \% recovery analysis, the SAX and MET standards, three distinct concentrations were prepared and spiked with pre-analyzed tablet solution (SAX- $20 \mu \mathrm{g} / \mathrm{mL}$ and MET- $200 \mu \mathrm{g} / \mathrm{mL}$ ). Every determination is injected three times and was analyzed as per design protocol. The findings \% recoveries were $100.16-100.66 \%$ for SAX and $99.65-100.73 \%$ for MET, and RSD \% levels were $0.11-0.92 \%$ for SAX and $0.05-0.30 \%$ for MET, respectively. The findings of $\%$ recovery studies for SAX and MET are presented in Table 2 .

Table 2. \% Recovery and precision investigation for SAX and MET.

\begin{tabular}{|c|c|c|c|c|c|c|c|c|}
\hline \multicolumn{2}{|c|}{$\begin{array}{l}\text { Initial } \\
\text { Amount } \\
{[\mu \mathrm{g} / \mathrm{mL}, \mathrm{n}=3]}\end{array}$} & \multirow[t]{2}{*}{$\begin{array}{l}\text { Level of } \\
\text { recovery } \\
\text { study }\end{array}$} & \multicolumn{2}{|c|}{$\begin{array}{l}\text { Total Amount } \\
\text { found } \\
{[\mu \mathrm{g} / \mathrm{mL}]}\end{array}$} & \multicolumn{2}{|c|}{ \% Recovery } & \multicolumn{2}{|c|}{ \% RSD } \\
\hline & & & SAX & MET & SAX & MET & SAX & MET \\
\hline \multicolumn{2}{|l|}{20} & $80 \%$ & 36.03 & 359.68 & 100.19 & 99.80 & 0.83 & 0.30 \\
\hline \multicolumn{2}{|l|}{20} & $100 \%$ & 40.03 & 399.31 & 100.16 & 99.65 & 0.11 & 0.19 \\
\hline \multicolumn{2}{|c|}{20} & $120 \%$ & 44.15 & 441.75 & 100.66 & 100.73 & 0.92 & 0.05 \\
\hline \multicolumn{2}{|c|}{$\begin{array}{l}\text { Concentration } \\
{[\mu \mathrm{g} / \mathrm{mL}, \mathrm{n}=3]}\end{array}$} & $\begin{array}{l}\text { Precision } \\
\text { analysis }\end{array}$ & \multicolumn{2}{|c|}{$\begin{array}{l}\text { Total Amount } \\
\text { found } \\
{[\mu \mathrm{g} / \mathrm{mL}]}\end{array}$} & \multicolumn{2}{|c|}{$\begin{array}{l}\text { \% Amount } \\
\text { found }\end{array}$} & \multicolumn{2}{|c|}{$\%$ RSD } \\
\hline 20 & 300 & \multirow{3}{*}{$\begin{array}{l}\text { Intra-day } \\
\text { Precision }\end{array}$} & 20.03 & 298.35 & 100.20 & 99.45 & 0.65 & 0.45 \\
\hline 30 & 400 & & 29.97 & 397.74 & 99.92 & 99.43 & 0.36 & 0.20 \\
\hline 40 & 500 & & 39.91 & 500.20 & 99.78 & 100.04 & 0.88 & 0.66 \\
\hline 20 & 300 & \multirow{3}{*}{$\begin{array}{l}\text { Intra-day } \\
\text { Precision }\end{array}$} & 19.89 & 299.39 & 99.47 & 99.79 & 0.95 & 0.34 \\
\hline 30 & 400 & & 29.85 & 400.30 & 99.51 & 99.82 & 0.49 & 0.47 \\
\hline 40 & 500 & & 39.64 & 503.03 & 99.11 & 100.60 & 0.51 & 0.36 \\
\hline 30 & 400 & Repeatability & 30.00 & 397.24 & 100.02 & 99.31 & 0.22 & 0.24 \\
\hline
\end{tabular}

\subsubsection{Precision.}

The precision of the designed UHPLC method was addressed for intra-day and interday precision and repeatability assay variability. The outcomes of it were addressed as RSD 
$\%$. The 20, 30, and $40 \mu \mathrm{g} / \mathrm{mL}$ of SAX and 300, 400, and $500 \mu \mathrm{g} / \mathrm{mL}$ of MET (three distinct concentrations of calibration of plots) were addressed using assay at different time frame on vary same day for intra-day precision and as a result of continuous for three successive days of analysis as per guideline of ICH. Likewise, repeatability variability was assessed using six determinations of $30 \mu \mathrm{g} / \mathrm{mL}$ of SAX and $400 \mu \mathrm{g} / \mathrm{mL}$ of MET concentrations. The findings of precision of assay variability for SAX and MET are presented in Table 2.

\subsubsection{Sensitivity.}

To calculate the sensitivity of the designed UHPLC method, LOD and LOQ were epitomized. The LOD and LOQ were calculated using standard deviation (N) of outcomes of the $\mathrm{SAX}$ and MET $(\mathrm{n}=3)$ and calibration curve slope $(\mathrm{B})$. The formulae exploited were LOD = $3.3 \times \mathrm{N} / \mathrm{B}$ and $\mathrm{LOQ}=10 \times \mathrm{N} / \mathrm{B}$. Serial working dilutions of $10-30 \mu \mathrm{g} / \mathrm{mL}$ of SAX and 100 $-300 \mu \mathrm{g} / \mathrm{mL}$ of MET ranges have been confirmed and examined. The planned method recorded LOD and LOQ values of $0.21 \mu \mathrm{g} / \mathrm{mL}$ and $0.66 \mu \mathrm{g} / \mathrm{mL}$ for SAX and $1.16 \mu \mathrm{g} / \mathrm{mL}$ and $3.53 \mu \mathrm{g} / \mathrm{mL}$ for MET, respectively. Hence, it was concluded that the design UHPLC method had ultimate sensitivity to the solvent system.

\subsubsection{Robustness.}

Robustness analysis of the designed UHPLC method was carried out by attempting to make significant changes in \% proportion of acetonitrile in a solvent system, the temperature of the column oven compartment, and flow rate. The influence of each of the independent variables was determined for the peak areas of SAX and MET. The selected independent variables for this analysis were varied as \% proportion of acetonitrile $(10-20 \% \mathrm{v} / \mathrm{v})$, the temperature of column oven compartment $\left(25-35^{\circ} \mathrm{C}\right)$, and flow rate $(0.3-0.5 \mathrm{~mL} / \mathrm{min})$.

\begin{tabular}{|c|c|c|}
\hline \multirow[t]{2}{*}{ Parameters } & \multicolumn{2}{|c|}{ UHPLC Method } \\
\hline & SAX & MET \\
\hline \multicolumn{3}{|l|}{ Linearity } \\
\hline Range $(\mu \mathrm{g} / \mathrm{mL})$ & $10-60$ & $100-600$ \\
\hline Determination coefficient $\left(\mathrm{r}^{2}\right)$ & 0.9989 & 0.9979 \\
\hline \multicolumn{3}{|l|}{ Accuracy } \\
\hline Average recovery $\left(\% \pm \mathrm{SD}^{1}\right)$ & $100.33 \pm 0.62$ & $100.06 \pm 0.18$ \\
\hline RSD \% & 0.62 & 0.18 \\
\hline \multicolumn{3}{|l|}{ Precision } \\
\hline Intra-day precision $\left(\mathrm{RSD}^{2} \%\right)$ & $0.36-0.88$ & $0.20-0.66$ \\
\hline Inter-day precision (RSD \%) & $0.49-0.95$ & $0.34-0.47$ \\
\hline Repeatability (RSD \%) & 0.22 & 0.24 \\
\hline \multicolumn{3}{|l|}{ Sensitivity } \\
\hline LOD $(\mu \mathrm{g})$ & 0.21 & 1.16 \\
\hline LOQ $(\mu \mathrm{g}$ & 0.66 & 3.53 \\
\hline Robustness & \multicolumn{2}{|c|}{ Robust } \\
\hline Specificity & \multicolumn{2}{|c|}{ Specific } \\
\hline
\end{tabular}

It was recognized that selected independent variables did not positively influence the analysis of SAX and MET. Analysis of robustness experiment has been addressed with 40 $\mu \mathrm{g} / \mathrm{mL}$ of SAX and $400 \mu \mathrm{g} / \mathrm{mL}$ of MET concentrations. The results of robustness experiments are presented in Table 3. 
3.2.7. Specificity and selectivity.

Specificity is the process for experimentally determining the interest of the analyte in the context of components that can also be supposed to present in the sample matrix; thus, selectivity is the process for qualitatively defining the interest of the analyte in the context of components likely to be present in the sample matrix. The designed UHPLC method is quite well selective and specific. It was noticed that there was no other specific intervention was recorded around the Rt of SAX and MET; neither the baseline exhibits a substantial unavoidable noise. The summary of validation parameters is present in Table 3.

\subsubsection{Application of marketed FDC's of SAX and MET.}

The designed UHPLC method was successfully explored for the quantification of SAX and MET in FDC's. The assay of SAX and MET in Kombiglyze XR (label claim SAX- $5 \mathrm{mg}$ and MET- $1000 \mathrm{mg}$ and label claim SAX- $5 \mathrm{mg}$ and MET- $500 \mathrm{mg}$ ) were recorded Table 4. A higher percentage of an analyte assay is preferred when developing an analytical procedure because it allows other researchers to examine similar drug candidates or various pharmaceutical FDC types regularly.

Table 4. Assay of marketed FDC's of SAX and MET.

\begin{tabular}{|c|c|c|c|c|c|c|}
\hline \multirow[t]{3}{*}{ Analytes } & \multicolumn{6}{|c|}{ Marketed FDC's } \\
\hline & \multicolumn{3}{|c|}{$\begin{array}{l}\text { Kombiglyze XR [label claim SAX- } 5 \text { mg and } \\
\text { MET- } 1000 \mathrm{mg} \text { ] }\end{array}$} & \multicolumn{3}{|c|}{$\begin{array}{l}\text { Kombiglyze XR [label claim SAX- } 5 \mathrm{mg} \text { and } \\
\text { MET- } 500 \mathrm{mg} \text { ] }\end{array}$} \\
\hline & $\begin{array}{l}\text { Taken }[\mu \mathrm{g} / \mathrm{mL} \text {, } \\
\mathrm{n}=6]\end{array}$ & Mean $\% \pm$ SD $^{1}$ & RSD $^{2} \%$ & $\begin{array}{l}\text { Taken }[\mu \mathrm{g} / \mathrm{mL}, \\
\mathrm{n}=6]\end{array}$ & Mean \pm SD & RSD \% \\
\hline SAX & 20 & $99.92 \pm 0.62$ & 0.62 & 20 & $99.92 \pm 0.62$ & 0.25 \\
\hline MET & 200 & $99.18 \pm 0.21$ & 0.21 & 200 & $99.33 \pm 0.10$ & 0.10 \\
\hline
\end{tabular}

\subsection{Stress degradation studies of SAX and MET.}

The investigating stress conditions and retention time of SAX and MET degradation products are depicted in Table 5 and Table 6. The UHPLC chromatogram of SAX and MET standard (Figure 2) represented single symmetrical peaks at $2.687 \pm 0.022 \mathrm{~min}$ and $1.856 \pm$ $0.03 \mathrm{~min}$. Acidic hydrolysis caused one degradation product for SAX and four degradation products for MET as shown in Figure 3, three degradation products for SAX, and two degradation products for MET were formed through alkaline hydrolysis as shown in Figure 4. While at neutral conditions, SAX and MET were found to be stable. The oxidative stress testings in $6 \% \mathrm{H}_{2} \mathrm{O}_{2}$ formed one degradation product for MET; no significant degradation was noticed for SAX as shown in Figure 5. At the same time, photolysis on the introduction of solid standards of analytes produced two degradants of SAX and four degradants for MET as shown in Figure 6. The thermal stress (dry and wet heat) produced four degradation products for SAX and six degradation products for MET, as shown in Figure 7.

In all cases, the anticipated UHPLC method's capability to analyzed the SAX and MET with no obstruction from degradation products. Indicating the stability-indicating potential of the anticipated investigation addresses the specificity of the method. 
Table 5. Findings of stress studies for SAX.

\begin{tabular}{|c|c|c|c|}
\hline Stressor conditions & $\begin{array}{l}\text { Number of } \\
\text { Degradants }\end{array}$ & Rt of degradants (min) & $\%$ Degradation \\
\hline \multicolumn{4}{|l|}{ Acidic hydrolysis } \\
\hline $1 \mathrm{M} \mathrm{HCL}$ reflux for 80 for $2 \mathrm{~h}$ & 01 & 1.986 & 8.73 \\
\hline \multicolumn{4}{|l|}{ Alkaline hydrolysis } \\
\hline \multirow[t]{3}{*}{$2 \mathrm{M} \mathrm{NaOH}$ at $80^{\circ} \mathrm{C}$ for $2 \mathrm{~h}$} & \multirow[t]{3}{*}{03} & 2.375 & 7.64 \\
\hline & & 2.700 & 9.83 \\
\hline & & 3.155 & 9.77 \\
\hline \multicolumn{4}{|l|}{ Neutral hydrolysis } \\
\hline At room temperature for 7 days & 0 & \multicolumn{2}{|c|}{ Stable } \\
\hline \multicolumn{4}{|l|}{ Oxidation } \\
\hline $6 \% \mathrm{H}_{2} \mathrm{O}_{2}$ at room temperature for 2 days & 0 & \multicolumn{2}{|c|}{ Stable } \\
\hline \multicolumn{4}{|l|}{ Photolysis } \\
\hline \multirow{2}{*}{$\begin{array}{l}\geq 360 \mathrm{Wh} / \mathrm{m} 2 \text { at } 30^{\circ} \mathrm{C} \text { with } \mathrm{UV} \text { radiation i.e., for } \\
\text { short UV-254 } \mathrm{nm} \text { and long UV-360 } \mathrm{nm} \text { for } 6 \\
\text { consecutive days }\end{array}$} & \multirow[t]{2}{*}{02} & 1.751 & 3.64 \\
\hline & & 2.946 & 1.63 \\
\hline \multicolumn{4}{|l|}{ Thermal degradation } \\
\hline $\begin{array}{l}\text { Dry heat } \\
\text { Sealed ampoule consisting of } 50 \mathrm{mg} \text { of SAX at } 80 \\
{ }^{\circ} \mathrm{C} \text { for } 10 \mathrm{~h}\end{array}$ & 0 & \multicolumn{2}{|c|}{ Stable } \\
\hline \multirow{4}{*}{$\begin{array}{l}\text { Wet heat } \\
\text { Digital controlled thermostatic hot air oven at } 80 \\
{ }^{\circ} \mathrm{C} \text { for } 5 \mathrm{~h}\end{array}$} & \multirow[t]{4}{*}{04} & 0.788 & 4.76 \\
\hline & & 1.286 & 2.58 \\
\hline & & 2.268 & 8.73 \\
\hline & & 2.562 & 12.80 \\
\hline
\end{tabular}

Table 6. Findings of stress studies for MET.

\begin{tabular}{|c|c|c|c|}
\hline Stressor conditions & $\begin{array}{l}\text { Number of } \\
\text { Degradants }\end{array}$ & Rt of degradants (min) & $\%$ Degradation \\
\hline \multicolumn{4}{|l|}{ Acidic hydrolysis } \\
\hline \multirow[t]{4}{*}{$1 \mathrm{M} \mathrm{HCL}$ reflux for 60 for $45 \mathrm{~min}$} & \multirow[t]{4}{*}{04} & 1.686 & 12.81 \\
\hline & & 1.813 & 19.69 \\
\hline & & 2.157 & 9.89 \\
\hline & & 2.334 & 0.99 \\
\hline \multicolumn{4}{|l|}{ Alkaline hydrolysis } \\
\hline \multirow[t]{2}{*}{$2 \mathrm{M} \mathrm{NaOH}$ at room temperature for 3 days } & \multirow[t]{2}{*}{02} & 2.106 & 27.39 \\
\hline & & 2.358 & 13.28 \\
\hline \multicolumn{4}{|l|}{ Neutral hydrolysis } \\
\hline At room temperature for 7 days & 0 & \multicolumn{2}{|c|}{ Stable } \\
\hline \multicolumn{4}{|l|}{ Oxidation } \\
\hline $6 \% \mathrm{H}_{2} \mathrm{O}_{2}$ at room temperature for 2 days & 01 & 2.402 & 12.53 \\
\hline \multicolumn{4}{|l|}{ Photolysis } \\
\hline \multirow{4}{*}{$\begin{array}{l}\geq 360 \mathrm{Wh} / \mathrm{m} 2 \text { at } 30^{\circ} \mathrm{C} \text { with } \mathrm{UV} \text { radiation i.e., for } \\
\text { short } \mathrm{UV}-254 \mathrm{~nm} \text { and long } \mathrm{UV}-360 \mathrm{~nm} \text { for } 6 \\
\text { consecutive days }\end{array}$} & \multirow[t]{4}{*}{04} & 1.198 & 3.91 \\
\hline & & 1.301 & 10.34 \\
\hline & & 1.668 & 0.87 \\
\hline & & 2.179 & 0.91 \\
\hline \multicolumn{4}{|l|}{ Thermal degradation } \\
\hline \multirow[t]{2}{*}{ Dry heat } & \multirow[t]{2}{*}{03} & 0.867 & 1.12 \\
\hline & & 1.189 & 2.25 \\
\hline
\end{tabular}




\begin{tabular}{l|c|c|c}
\hline Stressor conditions & $\begin{array}{c}\text { Number of } \\
\text { Degradants }\end{array}$ & Rt of degradants (min) & \% Degradation \\
\hline $\begin{array}{l}\text { Sealed ampoule consisting of } 100 \mathrm{mg} \text { of MET at } \\
80^{\circ} \mathrm{C} \text { for } 10 \mathrm{~h}\end{array}$ & & 1.478 & 4.62 \\
\hline $\begin{array}{l}\text { Wet heat } \\
\text { Digital controlled thermostatic hot air oven at } 80\end{array}$ & 03 & 1.088 & 1.67 \\
${ }^{\circ} \mathrm{C}$ for $5 \mathrm{~h}$ & & 1.489 & 3.81 \\
& &
\end{tabular}

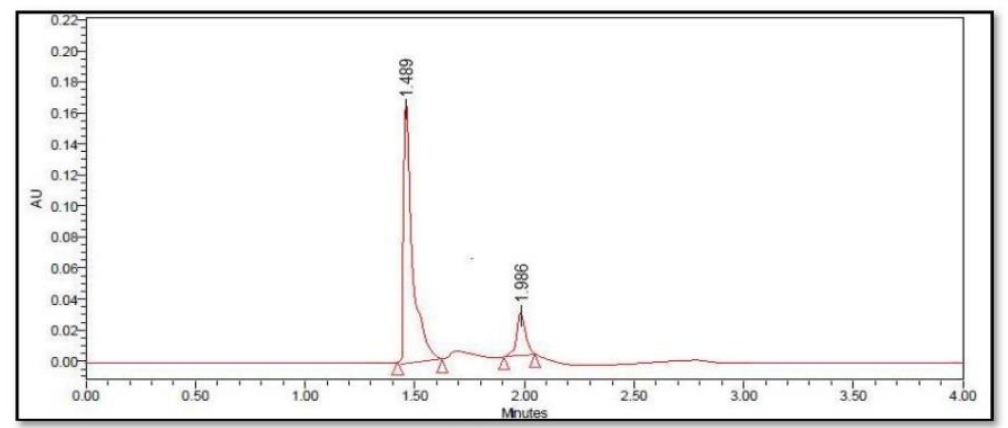

(a)

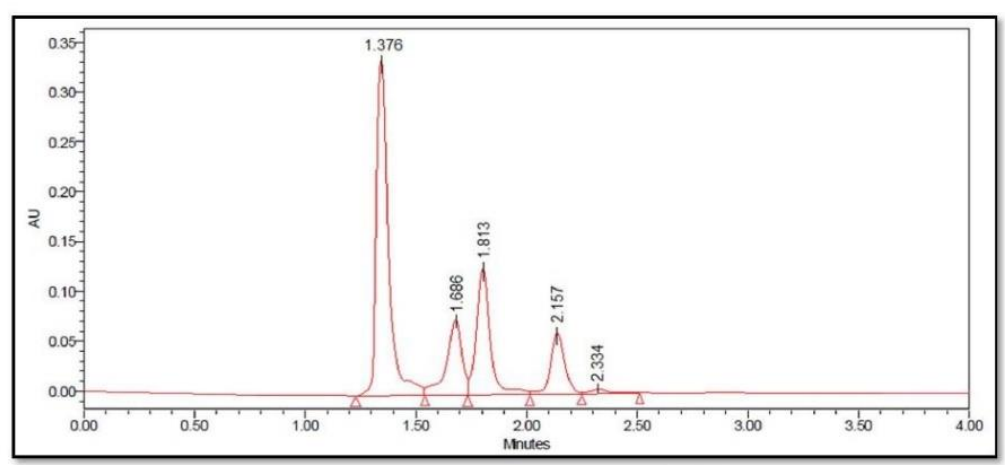

(b)

Figure 3. (a) Chromatogram of acidic hydrolysis of SAX; (b) Chromatogram of acidic hydrolysis of MET.

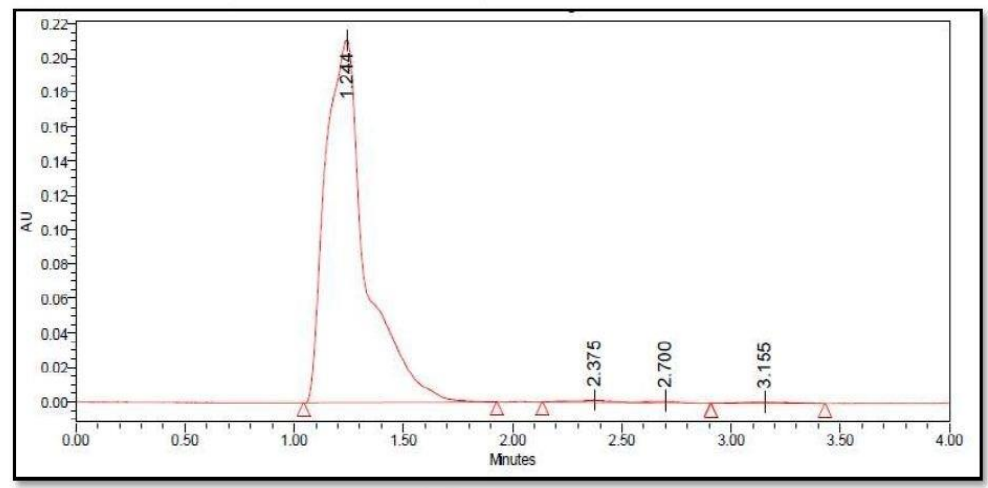

(a)

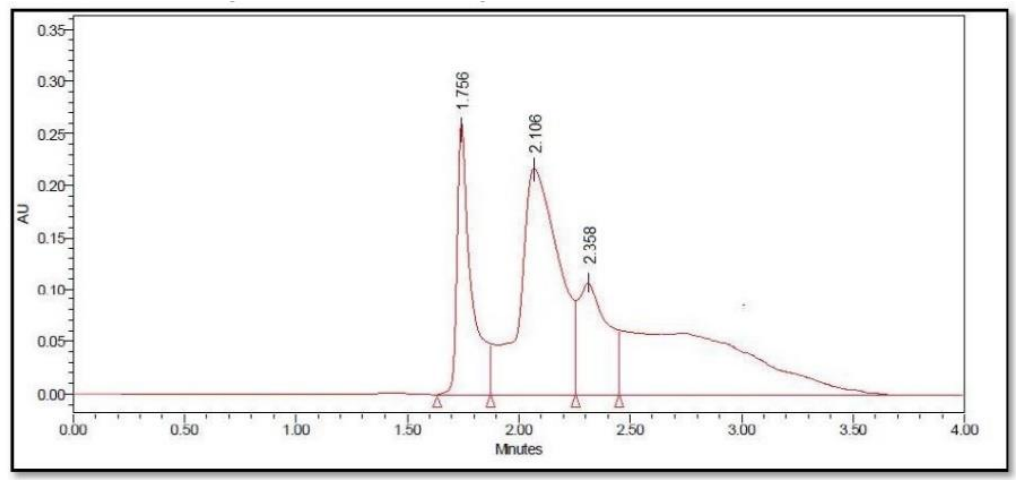

(b)

Figure 4. (a) Chromatogram of alkaline hydrolysis of SAX; (b) Chromatogram of alkaline hydrolysis of MET. 


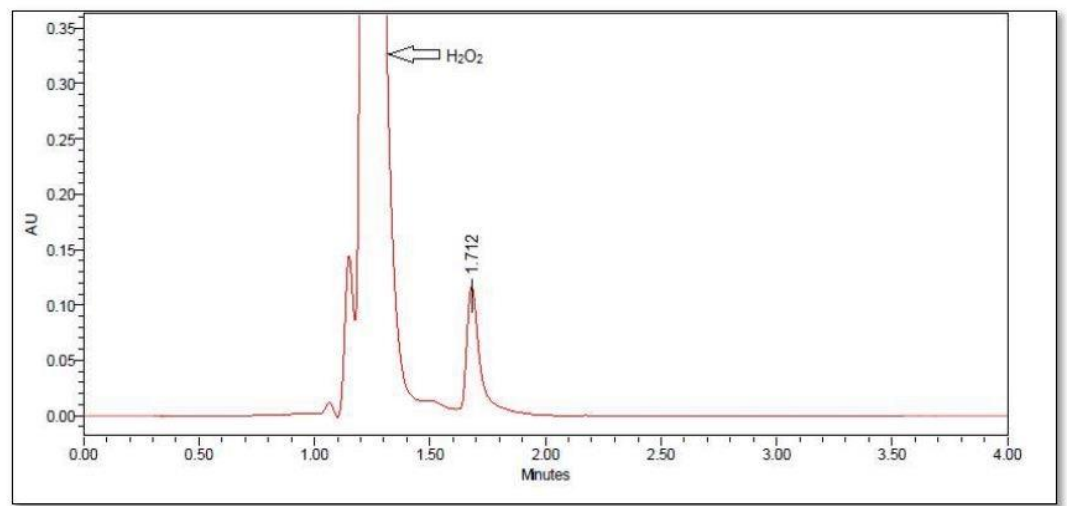

(a)

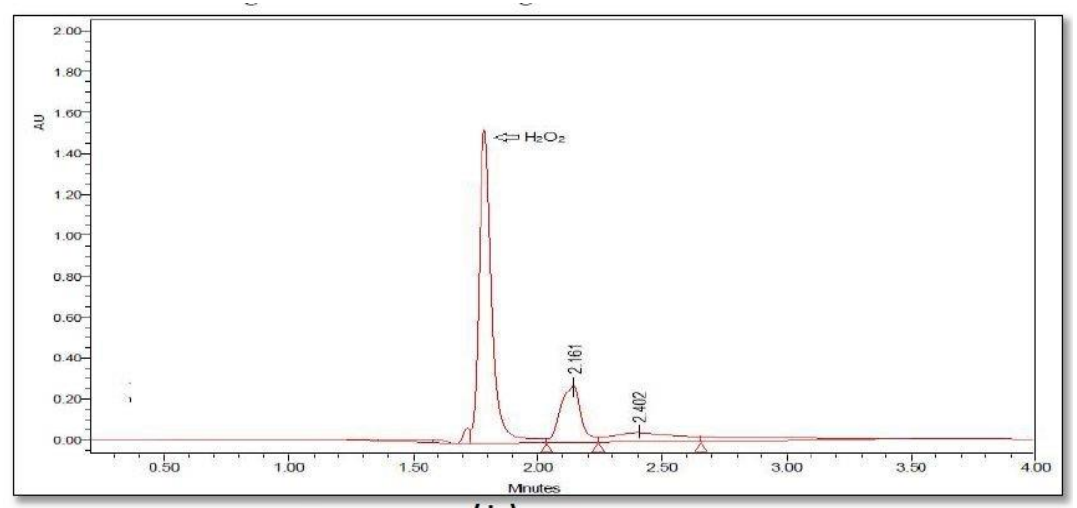

(b)

Figure 5. (a) Chromatogram of oxidative degradation of SAX; (b) Chromatogram of oxidative degradation of MET.

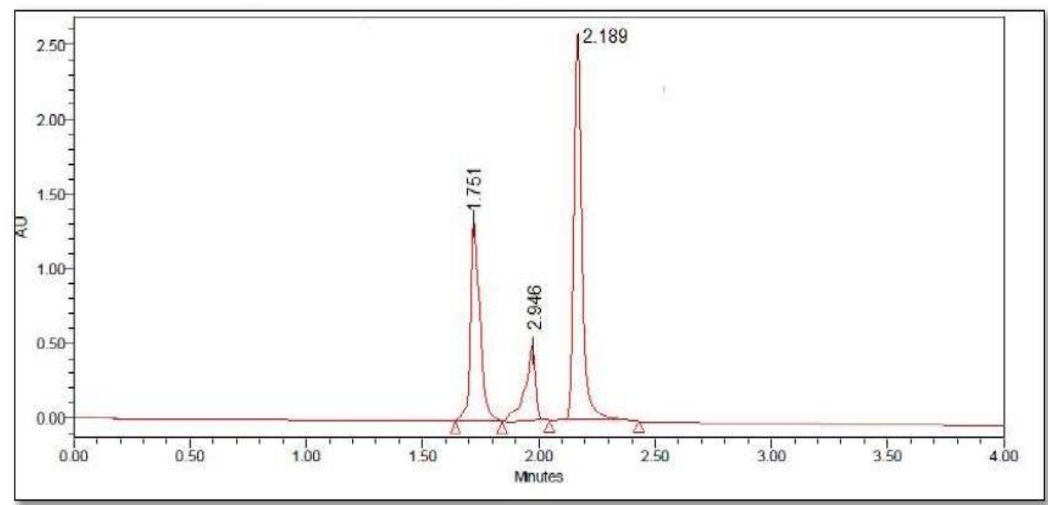

(a)

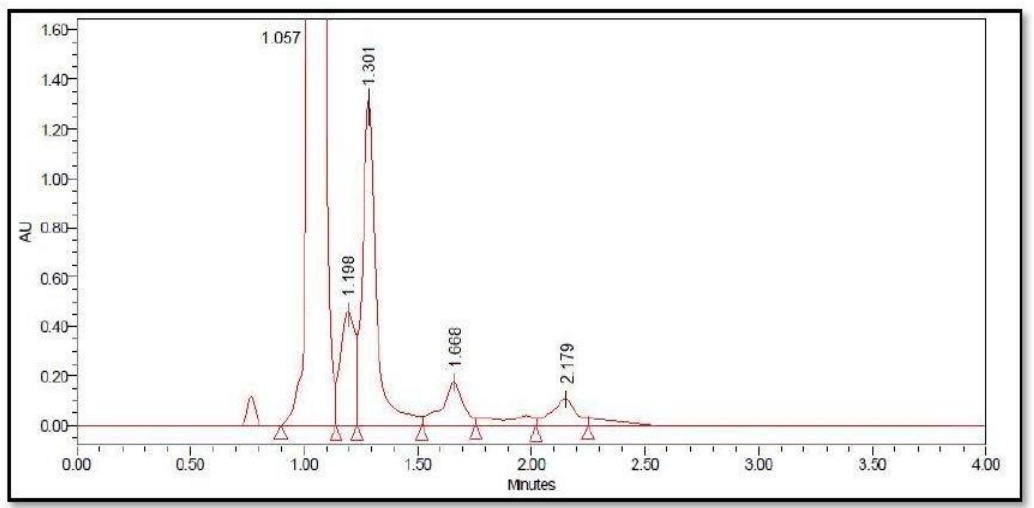

(b)

Figure 6. (a) Chromatogram of photolysis degradation of SAX; (b) Chromatogram of photolysis degradation of MET. 


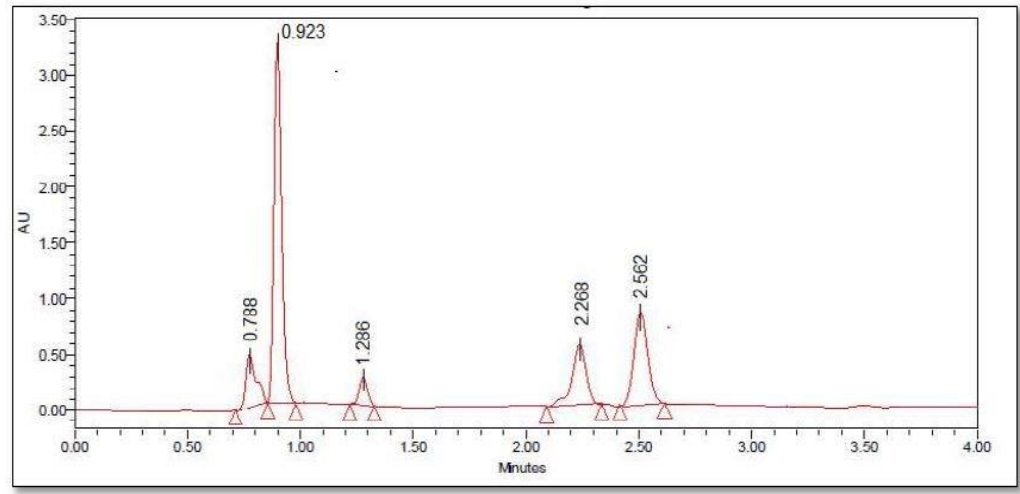

( a )

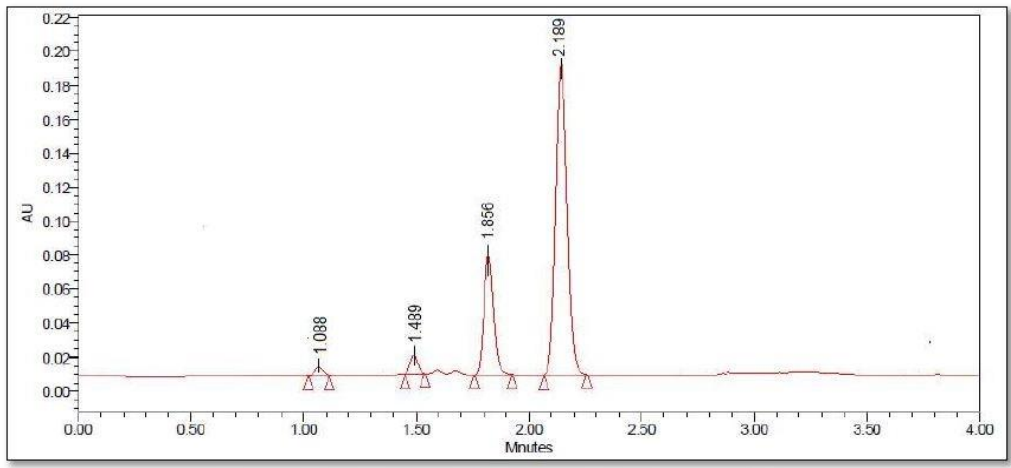

(b)

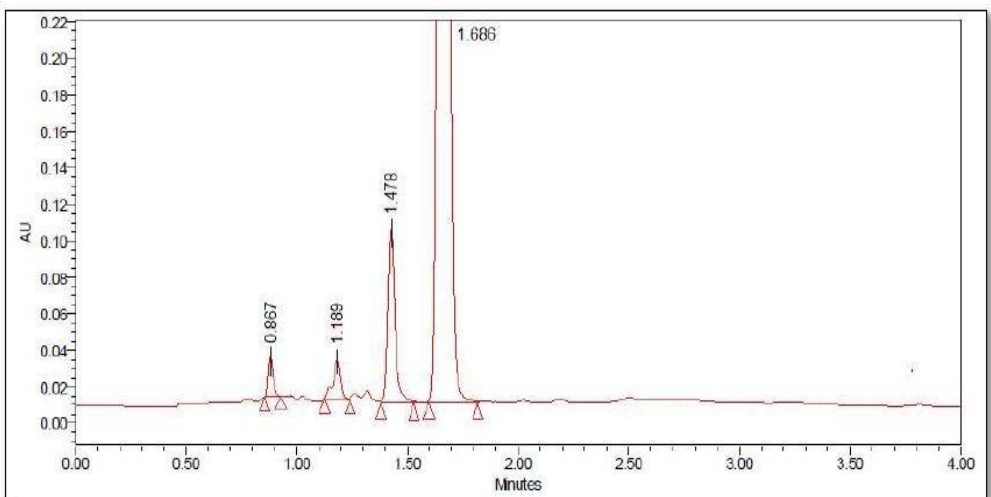

(c)

Figure 7. (a) Chromatogram of thermal degradation (dry and wet heat) of SAX; (b) Chromatogram of thermal degradation (wet heat) of MET; (c) Chromatogram of thermal degradation (dry heat) of MET.

\section{Conclusion}

A novel and rapid stability-indicating UHPLC assay method was developed and successfully validated for the simultaneous quantification of SAX and MET in pharmaceutical FDCs. Complete forced degradation analysis of SAX and MET behavior was carried out under acidic, basic, neutral, oxidation, photolysis, and thermal conditions. SAX was found to be degraded in acidic, basic, photolysis, and thermal stress conditions but was stable in oxidation and neutral conditions; MET, on the other hand, was found to be degraded in all stressed conditions except neutral hydrolysis. The developed UHPLC method was cost-effective, efficient, and specific. It can be used for the quality control laboratories to quantify SAX and MET in FDC's.

\section{Funding}




\section{Acknowledgments}

The authors acknowledge the support provided Institute of Pharmacy, NIMS University, Jaipur, Rajasthan, India, for the present work.

\section{Conflicts of interest}

The authors declare no conflict of interest.

\section{References}

1. Scheen, A.J. Saxagliptin plus metformin combination in patients with type 2 diabetes and renal impairment. Expert Opin. Drug Metab. Toxicol. 2012, 8, 383-394, https://doi.org/10.1517/17425255.2012.658771.

2. Vaag, A.; Lund, S.S. Insulin initiation in patients with type 2 diabetes mellitus: treatment guidelines, clinical evidence and patterns of use of basal vs premixed insulin analogues. Eur. J. Endocrinol. 2012, 166, 159-170, https://doi.org/10.1530/EJE-11-0022.

3. Bailey, C.J. Metformin: Effects on Micro and Macrovascular Complications in Type 2 Diabetes. Cardiovasc. Drugs Ther. 2008, 22, 215-224, https://doi.org/10.1007/s10557-008-6092-0.

4. Sola, D.; Rossi, L.; Schianca, G.P.C.; Maffioli, P.; Bigliocca, M.; Mella, R.; Corlianò, F.; Fra, G.P.; Bartoli, E.; Derosa, G. Sulfonylureas and their use in clinical practice. Arch. Med. Sci. 2015, 11, 840-848, https://doi.org/10.5114/aoms.2015.53304.

5. Derosa, G.; Maffioli, P. Patient considerations and clinical utility of a fixed dose combination of saxagliptin/metformin in the treatment of type 2 diabetes. Diabetes. Metab. Syndr. Obes. 2011, 4, 263-271, https://doi.org/10.2147/DMSO.S16361.

6. Scheen, A.J. A review of gliptins in 2011. Expert Opin. Pharmacother. 2012, 13, 81-99, https://doi.org/10.1517/14656566.2012.642866.

7. Scheen, A.J. Metformin + saxagliptin for type 2 diabetes. Expert Opin. Pharmacother. 2012, 13, 139-146, https://doi.org/10.1517/14656566.2012.642867.

8. Shah, P.A.; Shah, J. V; Sanyal, M.; Shrivastav, P.S. LC-MS/MS analysis of metformin, saxagliptin and 5hydroxy saxagliptin in human plasma and its pharmacokinetic study with a fixed-dose formulation in healthy Indian subjects. Biomed. Chromatogr. 2017, 31, e3809, https://doi.org/10.1002/bmc.3809.

9. Peng, Y.; Chang, Q.; Yang, N.; Gu, S.; Zhou, Y.; Yin, L.; Aa, J.; Wang, G.; Sun, J. Quantitative determination of metformin, saxagliptin and 5-hydroxy saxagliptin simultaneously by hydrophilic interaction liquid chromatography - electrospray ionization mass spectrometry and its application to a bioequivalence study with a single-pill com. J. Chromatogr. B 2018, 1081-1082, 109-117, https://doi.org/10.1016/j.jchromb.2018.02.007.

10. Donepudi, S.; Achanta, S. Simultaneous Estimation of Saxagliptin and Dapagliflozin in Human Plasma by Validated High Performance Liquid Chromatography - Ultraviolet Method. Turkish J. Pharm. Sci. 2019, 16, 227-233, https://doi.org/10.4274/tjps.galenos.2018.46547.

11. Al-Bratty, M.; Alhazmi, H.; Javed, S.; Lalitha, K.G.; Asmari, M.; Wölker, J.; El Deeb, S. Development and Validation of LC-MS/MS Method for Simultaneous Determination of Metformin and Four Gliptins in Human Plasma. Chromatographia 2017, 80, 891-899, https://doi.org/10.1007/s10337-017-3288-0.

12. Shah, P.A.; Shrivastav, P.S.; Sharma, V.; Yadav, M.S. Challenges in simultaneous extraction and chromatographic separation of metformin and three SGLT-2 inhibitors in human plasma using LC-MS/MS. J. Pharm. Biomed. Anal. 2019, 175, 112790, https://doi.org/10.1016/j.jpba.2019.112790.

13. Zhong, G.; Bi, H.; Zhou, S.; Chen, X.; Huang, M. Simultaneous determination of metformin and gliclazide in human plasma by liquid chromatography-tandem mass spectrometry: application to a bioequivalence study of two formulations in healthy volunteers. J. Mass Spectrom. 2005, 40, 1462-1471, https://doi.org/10.1002/jms.907.

14. Wattamwar, T.; Mungantiwar, A.; Gujar, S.; Pandita, N. Development of LC-MS/MS method for simultaneous determination of Canagliflozin and Metformin in human plasma and its pharmacokinetic application in Indian population under fast and fed conditions. J. Chromatogr. B 2020, 1154, 122281, https://doi.org/10.1016/j.jchromb.2020.122281.

15. Gurav, S.B.; Manish, N. Development and Validation of Novel Stability- Indicating LC Method for the Determination of Saxagliptin and Metformin. Indian J. Pharm. Educ. Res. 2020, 54, s350-s357, 
https://doi.org/10.5530/ijper.54.2s.93.

16. Singh, N.; Bansal, P.; Maithani, M.; Chauhan, Y. Development and validation of a stability-indicating RPHPLC method for simultaneous determination of dapagliflozin and saxagliptin in fixed-dose combination. New J. Chem. 2018, 42, 2459-2466, https://doi.org/10.1039/C7NJ04260D.

17. Prasad, P.; Satyanaryana, K.; Krishnamohan, G. Development and Validation of a Method for Simultaneous Determination of Metformin and Saxagliptin in a Formulation by RP-HPLC. Am. J. Anal. Chem. 2015, 06, 841-850, https://doi.org/10.4236/ajac.2015.611080.

18. Merey, H.A.; Ramadan, N.K.; Diab, S.S.; Moustafa, A.A. Chromatographic methods for the simultaneous determination of binary mixture of Saxagliptin $\mathrm{HCl}$ and Metformin $\mathrm{HCl}$. Bull. Fac. Pharmacy, Cairo Univ. 2017, 55, 311-317, https://doi.org/10.1016/j.bfopcu.2017.04.002.

19. Nyola, D.N.; Govindasamy, J. Simultaneous estimation of saxagliptin hydrochloride and metformin hydrochloride in active pharmaceutical ingrident by RP-HPLC. AJPRHC 2012, 4, 70-77.

20. Umapathi, P.; Ayyappan, J.; Quine, S.D. Quantitative Determination of Metformin Hydrochloride in Tablet Formulation Containing Croscarmellose Sodium as Disintegrant by HPLC and UV Spectrophotometry. Trop. J. Pharm. Res. 2012, 11, https://doi.org/10.4314/tjpr.v11i1.14.

21. Moussa, B.A.; Mahrouse, M.A.; Fawzy, M.G. Application of experimental design in HPLC method optimization and robustness for the simultaneous determination of canagliflozin, empagliflozin, linagliptin, and metformin in tablet. Biomed. Chromatogr. 2021, e5155, https://doi.org/10.1002/bmc.5155.

22. Rana, K.; Sharma, P. Analytical Method Development and Validation for the Simultaneous Estimation of Metformin Hydrochloride and Alogliptin by RP-HPLC in Bulk and Tablet Dosage Forms. Res. J. Sci. Technol. 2021, 13, 111-118, https://doi.org/10.52711/2349-2988.2021.00017

23. Vetapalem, R.; Yejella, R.P.; Atmakuri, L.R. Development and Validation of a Stability Indicating RP-HPLC Method for Simultaneous Estimation of Teneligliptin and Metformin. Turkish J. Pharm. Sci. 2020, 17, 141147, https://doi.org/10.4274/tjps.galenos.2018.16768.

24. Maheen, S.; Rasul, A.; Khan, H.U.; Shah, M.; Saadullah, M.; Siddiqui, F.A.; Afzal, K.; Sharif, M. Development and Validation of a Sensitive HPLC Method for the Simultaneous Estimation of Saxagliptin and Enalapril in Human Plasma. Lat. Am. J. Pharm. 2020, 39, 1279-1285.

25. Sivagami, B.; Purushotham, A.; Sikdar, P.; Chandrasekar, R.; Babu, M. A Validated Method for The Simultaneous Estimation of Linagliptin and Metformin in Tablet Dosage Forms by RP-HPLC. Res. J. Pharm. Technol. 2020, 13, 1266-1270, https://doi.org/10.5958/0974-360X.2020.00233.4.

26. Abdelrahman, A.E., Maher, H.M. and Alzoman, N.Z. HPTLC method for the determination of metformin hydrochloride, saxagliptin hydrochloride, and dapagliflozin in pharmaceuticals. Curr. Anal. Chem. 2020, 16, 609-619, https://doi.org/10.2174/1573407215666190131123029.

27. El-Kimary, E.I.; Hamdy, D.A.; Mourad, S.S.; Barary, M.A. HPTLC Determination of Three Gliptins in Binary Mixtures with Metformin. J. Chromatogr. Sci. 2016, 54, 79-87, https://doi.org/10.1093/chromsci/bmv106.

28. El-Shoubashy, O.H.-E.; Beltagy, Y.A.E.M.; Issa, A.E.; El-Kafrawy, D.S. Comparative study of HPLC-DAD and HPTLC for the simultaneous determination of a new multitarget antidiabetic ternary mixture in combined tablets. JPC - J. Planar Chromatogr. - Mod. TLC 2020, 33, 59-70, https://doi.org/10.1007/s00764-01900003-1.

29. Reddy, C.H.M, Mubeen, G. Pal, M. HPTLC method for estimation of metformin hydrochloride. Biomed. Pharmacol. J. 2015, 1, 445-448.

30. Modi, D.K.; Patel, B.H. simultaneous determination of metformin hydrochloride and glipizide in tablet formulation by hptlc. J. Liq. Chromatogr. Relat. Technol. 2012, 35, 28-39, https://doi.org/10.1080/10826076.2011.593227.

31. Patel, M.; Shah, H.; Shah, U.; Patel, A.; Chokshi, A.; Vyas, N. Analytical Methods for Simultaneous Estimation of SGLT2 Inhibitor and DPP-4 Inhibitor in their Combination for Treatment of Type 2 Diabetes Mellitus. Lett. Appl. NanoBioScience 2020, 10, 1799-1815, https://doi.org/10.33263/LIANBS101.17991815.

32. Krishnan, B.; Mishra, D.K. Quality by Design based Development and Validation of RP-HPLC Method for Simultaneous Estimation of Sitagliptin and Metformin in Bulk and Pharmaceutical Dosage Forms. Int. J. Pharm. Investig. 2020, 10, 512-518, https://doi.org/10.5530/ijpi.2020.4.89.

33. Ahmed, H.M.; Omar, M.A.; Batakoushy, H.A.; Hamid, M.A.A. HPTLC-densitometric analysis of selected antidiabetic drugs in presence of their degradation products. Microchem. J. 2020, 154, 104560, https://doi.org/10.1016/j.microc.2019.104560.

34. Rageeb, Md.; Sufiyan, A.; Deore, C.; Shaikh, T.; Jain, B.; Imran, Md..; Stability Indicating RP-HPLC Method 
for Determination of Saxagliptin and Dapagliflozin in Bulk and Tablet Dosage Forms. J. Pharm. Sci. \& Res. 2020, 12, 499-506.

35. Stability Testing of New Drug Substances and Products. International Conference on Harmonization. IFPMA, Geneva 1993.

36. Stability Testing of New Drug Substances and Products. International Conference on Harmonisation. IFPMA, Geneva 2005.

37. Validation of analytical procedures: text and methodology. 2005, 1 . 